\title{
Occupational health and safety management systems: comparison between BS OHSAS 18001: 2007 and Italian Decree 81/2008
}

\author{
G. A. Degan, D. Lippiello \& M. Pinzari \\ Dipartimento di Ingegneria Meccanica e Industriale, \\ Università degli studi ROMA TRE, Italy
}

\begin{abstract}
Organizations of all kinds are increasingly concerned with demonstrating occupational health and safety $(\mathrm{OH} \& \mathrm{~S})$ performance by controlling their $\mathrm{OH} \& \mathrm{~S}$ risks, consistent with their policy and objectives. The OHSAS Standard is intended to provide organizations with the elements of an effective OH\&S management system that help organizations themselves achieve OH\&S objectives. As well known, they do so in the context of increasingly stringent legislation as introduced in Italy by Government Decree $\mathrm{N}^{\circ} 81 / 2008$ (D. Lgs. Gov. 81/08). Aim of the present work is that of comparing these two different approaches aimed to the same objective that is represented by a deep respect of OH\&S conditions at work. In particular the OHSAS 18001:07 Standard specifies requirements for an OH\&S management system to enable an organization to develop and implement a Policy and pursuing Objectives taking into account all applicable legal requirements and information about OH\&S risks. It is intended to apply to all types of Organizations and to accommodate diverse geographical, cultural and social conditions. Moreover it is based on the methodology known as Plan-Do-Check-Act (PDCA). This system model managing is based on four phases aimed to develop a continual improvement: the first step is that of establishing Objectives and Processes necessary to deliver results in accordance with the organization's OH\&S Policy. The following step is that of implementing the processes, then they are measured and monitored against policy objectives and legal requirements. Finally, actions to continually improve OH\&S performance are taken. According with this model, the present work is aimed to study and underline differences between BS OHSAS 18001 and D. Lgs. Gov. 81/08: moreover a comparison will be taken into account in order to
\end{abstract}


point out how the adoption of a such defined OH\&S management system satisfies legal requirements defined by Italian laws.

Keywords: occupational health and safety, BS OHSAS 18001:2007, Italian Decree $n^{\circ} 819^{\text {th }}$ April 2008 (D. Lgs. Gov. 81/08), OH\&S management systems.

\section{Introduction}

BS OHSAS 18001:2007 “Occupational health and safety management systems Requirements" specifies requirements for an occupational health and safety $(\mathrm{OH} \& \mathrm{~S})$ management system, to enable an organization to control its $\mathrm{OH} \& \mathrm{~S}$ risks and improve its performance. Many organizations are implementing an Occupational Health and Safety Management System (OHSMS) as part of their risk management strategy to address changing legislation and protect their workforce.

An OHSMS, in fact, promotes a safe and healthy working environment by providing a framework that allows organization to consistently identify and control its health and safety risks, reduce the potential for accidents, aid legislative compliance and improve overall performance.

BS OHSAS 18001:07 is the internationally recognized assessment specification for occupational health and safety management systems. It was developed by a selection of leading trade bodies, international standards and certification bodies to address a gap where no third-party certifiable international standard exists. Certifying your BS OHSAS 18001 management system enables an Organization to prove that it conforms to the specification and provides the following benefits:

- Potential reduction in the number of accidents

- Potential reduction in downtime and associated costs

- Demonstration of legal and regulatory compliance

- Demonstration to stakeholders of your commitment to health and safety

- Demonstration of an innovative and forward thinking approach

- Increased access to new customers and business partners

- Better management of health and safety risks, now and in the future

- Potential reduced public liability insurance costs

But above this, an important reference to BS OHSAS 18001:07 in Italian Laws is given in Government Decree ${ }^{\circ} 81 / 2008$. It is the very first time that an Italian Law explicitly cites an International OH\&S Standard, forcing, we can say, Organizations to adopt it. In particular the article n. 30 defines and establishes management and organization Models releasing administrative accountability for involved people or societies. British Standard 18001:2007 is among those Models. That implies that if an organization develops an occupational and health management systems as showed in the OHSAS 18001 standard, its accountable people do not have administrative responsibility for any related non conformity to legal requirements. This reference focuses managers attention on this Standard and represents another important reason according to organizations develop OH\&S management system. Moreover it is not specified 
that $\mathrm{OH} \& \mathrm{~S}$ system may be certified but the system itself is to be effectively implemented, documented and maintained.

This aspect implies some considerations and in particular the main one is that of defining the relationship between Italian Decree 81/08 and BS OHSAS 18001:2007. In particular OHSAS general requirements include commitment to at least comply with applicable legal requirements. But the main problem is that of pointing out what further requirements and aspects should be defined, developed and documented by an organization complied with applicable Italian laws to fulfil $\mathrm{OH} \& \mathrm{~S}$ standard.

\section{BS OHSAS 18001:2007: general features}

In order to point out these differences, the first step is based on a deep analysis of both process approaches. OH\&S management system for BS Standard is based on the methodology known as Plan Do Check Act (PDCA).

Before speaking of the methodology, it is possible to say that the very first step an Organization should move in order to establish, implement and maintain an OHSMS is define its Policy. According to definitions given in BS OHSAS 18001:07, Policy should be expressed citing the overall intentions and direction of the Organization related to its $\mathrm{OH} \& \mathrm{~S}$ performance. Give an Organizational Policy means, indeed, provide the framework for action and the setting of the OH\&S Objectives. Once defined the Policy it is possible to describe the implementation OH\&S system based on four cited phases (PDCA) that can be briefly described as follows:

- Plan means establishing the objectives and processes necessary to deliver results in accordance with organization's $\mathrm{OH} \& \mathrm{~S}$ policy

- Do is the phase of implementing processes planned

- Check is the phase of monitoring and measuring results and objectives

- Act is the phase aimed to guarantee continual improvement as for OH\&S performance.

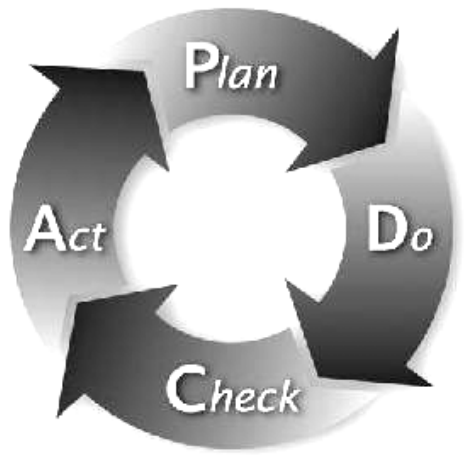

Figure 1: The Shewhart/Deming Cycle - PDCA. 
This management system is generally referred to as "process approach" and it is the same other management system are based on (ISO 9001 or ISO 14001 for example) and in fact BS OHSAS 18001 has been designed to be compatible with ISO 9001 and ISO 14001, to help organizations meet their health and safety obligations in an efficient manner.

Moreover the structure of BS OHSAS 18001 is based on some important requirements that are developed according with the process approach. The plan phase is first based on requirements about hazard identification, risk assessment and determining control then legal requirements are taken into account and finally definition of objectives and programmes is focused.

The following step is represented by implementation and operation of the system. This is characterized by definition of resources, roles, responsibility, accountability and authority but communication participation and consultation aspects are taken into account together with documents required and their controls. The final part is the based on performance measuring, monitoring and improvement.

It is important to underline the first difference between the BS standard structure and the model proposed by Italian Laws: in BS Standard is clearly stated the principle of continual improvement that is represented by a cyclical stream of the processes' phases (Deming cycle). In Decree 81 it is recommended a upload of risk assessment only if some changes or modifications occur to the organization itself.

But many differences may be pointed out not only from a general point of view, but comparing point by point the two approaches. According with phases addressed by BS OHSAS 18001 we can find these key areas:

- Planning for hazard identification, risk assessment and risk control

- OHSAS management programme

- Structure and responsibility

- Training, awareness and competence

- Consultation and communication

- Operational control

- Emergency preparedness and response

- $\quad$ Performance measuring, monitoring and improvement

The proposed comparison will be developed according with these features.

\section{BS OHSAS 18001 and Italian Decree 81/2008: planning for hazard identification, risk assessment and risk control}

In D. Lgs. Gov. $81 / 08$ risk analysis is defined as a duty for the employer that includes it in a document as stated in article 28. This documents shall include evaluation of all health and safety risks also including equipment and materials at workplace and infrastructures. Moreover it shall include the following points that are:

- A report about risk analysis and adopted evaluation criteria to approach risk analysis itself. 
- Prevention and protective actions to be adopted

- Program of defined actions to improve safety and health conditions at work

- Procedures to implement program of prevention/protective actions and related responsibles.

- Definition of workers' categories exposed to specific risks

The approach to the same matter is deeply different: in BS OHSAS the phase of risk analysis (but also hazard identification and determining controls) is referred to a planning phase in which the work is to begin. In D. Lgs. Gov. 81/08 the report about risks at work is developed on activities in progress. From this point of view it is interesting to note that an outline recent draft Decree $\left(31^{s t}\right.$ March 2009), that likeable will soon become National Law, explicitly declares that new Firms should realize the entire hazard identification and risk analysis not later than 90 days from the begin of activities...

Moreover in BS OHSAS different risks are taken into account and among them there are some features not considered in Decree 81: in the Italian Law there is mention only about risks related to changes (article 29) but nothing is said about proposed changes in work organization or worked materials, temporary changes or temporary modifications on activities, risks related to non routine activities, human behaviour, identified hazards originating outside the workplace capable of adversely affecting the health of workers.

Moreover in the Standard not only risks the workers are exposed to are considered but also those regarding people under the control of the Organization. In this context the reference to this matter in D. Lgs. Gov. 81/08 is that referred to contractors and suppliers. In D. Lgs. Gov. 81/08 (article 26) contractors and autonomous workers (people under Organization control) should be informed about risks they should be exposed to by a specific document, the so called DUVRI that is a report about risks originating from interference between two or more different firms activities in the same workplace and consequent controls to be adopted.

In general we may assert that risk assessment is dynamic as for the BS approach and takes into account different features concerning the Organization itself basing the entire process on a proactive approach. The D. Lgs. Gov. 81/08 risk evaluation approach seems, instead, a particular Employer duty and the concept of continuous monitoring of risk assessment and effectiveness controls is not always considered.

\section{BS OHSAS 18001 and Italian Decree 81/2008: training, awareness and competence, consultation and communication}

Another element to be underlined refers to training, participation of workers to $\mathrm{OH} \& \mathrm{~S}$ matters and consultation. In Italian decree training is considered a duty for the Employer (art. 37). In particular he shall ensure that workers are competent about $\mathrm{OH} \& \mathrm{~S}$ risks connected with their activity, prevention and 
protective measures adopted, but there is no mention about effectiveness of provided training or about different training level taking into account different levels of ability or language skills. Moreover in Italian Law the phase of monitoring workers' awareness about $\mathrm{OH} \& \mathrm{~S}$ risks or their competence about consequences of their work is not explicitly mentioned.

But in this key area the most important difference is that about workers' consultation and participation. In BS OHSAS workers are called to be involved in hazard identification, risk assessment and controls determination but above all in incident investigation. No mention of this aspect is done in Italian Law.

Workers, as for BS OHSAS 18001, are called to investigate about incident that means accidents (incident with related injury), and also near miss (dangerous occurrence without consequences) while only injuries with consequence of at least one day absence from workplace are recorded. The D. Lgs. Gov. 81/08 article 35, "Periodical Meeting" imposes that not less than once on a year the Employer and workers' Representatives should hold a meeting during which it is discussed about the Trend (number and incidence, frequency and seriousness) of the accident and professional illness work related. It is evident that even this element seems to confirm the typical reactive approach of the Italian Law.

This difference may be appreciated by considering that these data in BS OHSAS 18001 are used not only to investigate OH\&S conditions at work but they represents a measure of performance of OH\&S system itself. Moreover in BS OHSAS approach also contractors and autonomous workers are involved in consultation about $\mathrm{OH} \& \mathrm{~S}$ risks. Communication is, indeed, carefully established and implemented in BS OHSAS 18001. In particular OH\&S hazard, risks and management system are taken into account and communicated according with internal parts (among the various levels and functions of the organization), external parts (not only with contractors and autonomous workers but also visitors of workplace) and finally external interested parts.

In Italian Law this feature is dealt with the cited art. 35 in which the Employer has the duty of holding meetings in which $\mathrm{OH} \& \mathrm{~S}$ figures participate (employer himself, workers representatives, a work doctor, and OH\&S coordinator) and discuss about $\mathrm{OH} \& \mathrm{~S}$ matters. There is not a direct involvement of workers but only the election of a representative about OH\&S matters.

\section{BS OHSAS 18001 and Italian Decree 81/2008: checking phase}

An important step in BS OHSAS 18001 is represented by OH\&S system performance measurement and monitoring that shall provide both qualitative and quantitative measures on regular basis (BS OHSAS 4.5 Checking). Aim of the point 4.5 is indeed monitoring of the extent to which the Organization's OH\&S objectives are met and providing the framework about the effectiveness of controls, applied proactive and reactive measures and performances.

Moreover we can say that the most important phase of the 4.5 Checking Activity is the Audit one: Audit is a systematic, independent, documented 
process for obtaining useful evidences in order to evaluating if objectives are fulfilled. First of all, indeed, the Audit activity should determine whether the OHSMS conforms to the planned arrangements and has been properly implemented and maintained; than an Audit should determine whether the OHSMS is effective in meeting with Policy and planned Objectives. We should note that the D. Lgs. Gov. 81/08, because of its internal structure, does not provide any Audit activity. The entire hazard evaluation and risk analysis/assessment that includes the points "Program of defined actions to be improve $H \& S$ " and "Procedures to implement prevention/protective program and related responsible" seems to rule out definitively the Continual Improvement choice, making the Risk Evaluation (art. 28) a static and selffinishing activity.

\section{BS OHSAS 18001 and Italian Decree 81/2008: structure, accountability and responsibility}

The BS OHSAS 18001 defines strictly the boundary of Accountabilities and Responsibility for the OH\&S and the OHSMS (point 4.4.1.). Each Organization should, indeed, appoint a member (or members) of the top management with specific accountabilities for OH\&S. The top management (TM) appointee can be chosen irrespective of other responsibilities. This is impossible in the D. Lgs. Gov. 81/08 OH\&S management system that defines the Employer on the base of his specific activity and gives not any possibility to chose.

The TM appointee specific role and authority is defined in order to ensuring that the OHSMS is established, implemented and maintained; anyway he may delegate some of his duties to subordinates representatives, still retaining accountabilities. This specific expression establishes definitively the accountability-responsibility line.

The D. Lgs. Gov. 81/08 introduces the possibility of delegating duties (articles 16 and 17). The delegated duty should be recorded and the appointee should be declared able to act in terms of knowledge, organizational and financial autonomy. Once defined the capabilities of the appointee all the Employer's accountabilities can be moved away. The delegating activity does not in any way exclude the Employer vigilance duty (art.16), which remains the only Employer's duty related to a delegated one. There are only a couple of duties that the Employer can't delegate (art.17) that are the Risk Assessment activity and the OH\&S internal coordinator appointment.

According to this framework we should, at last note, another important conclusion: an Italian Employer loose accountabilities if delegates a duty to someone (D. Lgs. Gov. 81/08); but if the Employer is at once the TM OH\&S appointee the delegating activity can only transfer responsibilities.

\section{BS OHSAS 18001 vs. Italian D. Lgs. Gov. 81/08: review}

As a case study conclusion it is possible to say that there are several differences between the BS OHSAS 18001 and the D. Lgs. Gov. 81/08. Such differences 
could generate serious problems and conflicts for Italian Organizations that intend implement the OHSAS 18001 in our Country.

First difference and, we can say, the most relevant, consists in the approach itself to the OH\&S discipline: the BS OHSAS 18001 approach is always oriented to a proactive philosophy and the Management System proposed is obviously based on the effort of prevent an occurrence whereas prevent the recurrence or limit damages. This approaching method seems not always be present in the MS proposed by the D. Lgs. Gov. 81/08, and, instead, a reactive approach often find application in this MS.

We can also say that the Continual Improvement concept, that is the main basis of the BS OHSAS 18001 (e.g. Introduction of the BS OHSAS 18001), seems to be hiding in the D. Lgs. Gov. 81/08 MS. Indeed according to the abrogation of the D. Lgs. Gov. 626/94 the Residual Risk has been erased. The presence of Residual Risk, that should be appointed as that kind of risk that remains after the Risk Assessment and Controls Application process, could be considered as a permanent Employer's duty because, even if the Residual risk is defined as an acceptable risk, it should be taken into account sooner or later in a perspective of improvement the $\mathrm{OH} \& \mathrm{~S}$ parameters.

Obviously the reactive and structural approach, typical of the D. Lgs. Gov. $81 / 08$, can be found in the whole Management System and originates essential gaps: first of all the cited total lack of a preventive risk assessment and hazard evaluation (new firms and activities, new plants and machineries, new process etc.); on the other side we should even mention the lack of an methodological approach based on incident (with or without consequences) study as a preventive instrument and as a real improvement MS way.

\section{Conclusion and discussion}

The certification and implementation of occupational health and safety management systems have become a priority for many organizations. To investigate the status of implementing occupational health and safety management systems and to explore important performance indicators for OHSMSs' performance appraisal a survey was administered in order to evaluate if conformity can be found between the Standard's requirements and the actual national Italian Health and Safety requirements. The results of the survey indicated that the implementation of OHSAS 18001 in an Italian Organization might find on its path lots of problems. The most critical of these and, at the same time the most unexpected, is the inconformity between the Law and the Standard.

Substantially, this is a pioneering study (to be improved and enhanced) about the real possibility of OHSAS 18001 implementation in Italy and on the consequent imperative improvement to be enforced to the Health and Safety national Laws.

From this study the following priority point can be made. The key to successful implementation of OHSAS 18001 is greatly dependent on the reappraisal of the Residual Risk concept within Laws. It means the return of the 
Italian Laws corpus to the philosophy of the "Continual Improvement", first of all.

At last something should be said about the total absence in Italian Laws of the concept of Integration of Management Systems (Quality, Safety, Environmental). The integration of occupational safety health management system and environmental management system can, e.g., help companies to find solutions that handle both environmental and safety risks in an optimal way, therefore, further work is required to develop the integration of occupational safety health management system and environmental management system performance evaluation.

\section{References}

[1] ISO 9000:2005, Quality management systems - Fundamentals and vocabulary.

[2] ISO 9001:2000, Quality management systems - Requirements

[3] ISO 14001:2004, Environmental management systems - Requirements with guidance for use

[4] ISO 19011:2002, Guidelines for quality and/or environmental management systems auditing.

[5] BS OHSAS 18001:07, Occupational health and safety assessment series.

[6] Decreto Legislativo del Governo 9 aprile 2008, n. 81. Attuazione dell'articolo 1 della legge 3 agosto 2007, n. 123, in materia di tutela della salute e della sicurezza nei luoghi di lavoro. Gazzetta Ufficiale N. 101 del 30 Aprile 2008. Art.30 e s.m.i.

[7] Schema di decreto legislativo contenente disposizioni integrative e correttive al D. Lgs. 9 aprile 2008, n. 81, c.d. Testo Unico della sicurezza del lavoro (31 marzo 2009). 